\title{
OPTIMALISASI BIAYA DAN WAKTU PADA USAHA KERAJINAN KAYU HITAM DI SUMBER URIP EBONY DENGAN MENGGUNAKAN METODE HUNGARIAN
}

\author{
M. Maharani ${ }^{1}$, A. I. Jaya², dan A. Sahari ${ }^{3}$ \\ 1,2,3 Program Studi Matematika Jurusan Matematika \\ Fakultas Matematika dan IImu Pengetahuan Alam Universitas Tadulako \\ Jalan Sukarno-Hatta Km. 9 Palu 94118, Indonesia \\ 1marji_maharani@yahoo.com, 2jayaindraagus@gmail.com,3agus_sh@yahoo.com
}

\begin{abstract}
Palu as the Capital of Central Sulawesi province is known as one of the crafts made from ebony. Ebony wood craft industry in Palu begin to increase with the establishment of several business ebony, one of them is Sumber Urip Ebony Store that not only as a shop to sell the crafts, but at the same time as a place to produce the ebony wood crafts. This store have 9 workers and already have an adequate means of production. This study aimed is to propose the hungarian method to solve multi-objective assignment by optimizing the cost and time of production. From the results of the study is obtained that the total cost of producing all kinds of crafts is Rp. $8,080,000$, - with a total of 87 days. This indicates more efficient results when compared with the cost of Rp. 12.650 .000 , - with a total of 115 days at Sumber Urip Ebony Store.
\end{abstract}

Keywords $\quad$ : Assignments of Workers, Hungarian Method, Multi-objective Assignment, Optimize.

\section{ABSTRAK}

Palu sebagai Ibukota Provinsi Sulawesi Tengah dikenal sebagai salah satu penghasil kerajinan tangan berbahan baku kayu hitam. Kerajinan industri kayu hitam di Kota Palu mulai meningkat dengan berdirinya beberapa usaha kayu hitam, salah satunya adalah Toko Sumber Urip Ebony yang tak hanya sebagai toko untuk menjual, namun sekaligus tempat memproduksi kerajinan kayu hitam. Toko ini mempunyai 9 pekerja dan telah mempunyai alat produksi yang memadai. Penelitian ini bertujuan untuk mencari pendekatan dalam memecahkan masalah penugasan multi-objective dalam mengoptimalisasi biaya dan waktu dengan metode hungarian. Dari hasil penelitian diperoleh total biaya yang dikeluarkan untuk memproduksi semua jenis kerajinan adalah Rp. 8.080.000,dengan total waktu 87 hari. Perhitungan menggunakan penugasan multi- objective ini menunjukkan hasil yang lebih efisien bila dibandingkan dengan biaya yang dikeluarkan sebesar Rp. 12.650.000,- dengan total waktu 115 hari pada Toko Sumber Urip Ebony.

Kata Kunci $\quad$ : Penugasan Pekerja, Metode Hungarian, Penugasan Multi-objective, Optimalisasi. 


\section{PENDAHULUAN}

Palu sebagai ibukota Provinsi Sulawesi Tengah, dikenal sebagai salah satu penghasil kerajinan tangan berbahan baku kayu hitam ebony. Kerajinan industri di Kota Palu mulai meningkat dengan berdirinya beberapa usaha kayu hitam salah satunya pada toko Sumber Urip Ebony yang berada di jalan Sisinga Mangaraja No. 27, tak hanya toko untuk menjual namun sekaligus tempat memproduksi kayu hitam. Untuk memenuhi permintaan barang tersebut, maka pengusaha bekerja dengan 9 usaha skala rumah tangga yang tersebar di wilayah Kota Palu. 9 pekerja tersebut telah mempunyai alat produksi yang memadai.

Tidak dipungkiri bahwa, dalam dunia usaha terdapat persaingan untuk menghasilkan produk yang berkualitas tinggi agar mendapatkan keuntungan yang maksimal serta harus memperhatikan dampak atau efek lingkungan yang di timbulkan dari produk tersebut, perlu didukung keputusan yang tepat.

Salah satu bagian dari matematika yang dapat dijadikan pertimbangan untuk pengambilan keputusan adalah program linear (linear programming) yang merupakan suatu model yang dapat digunakan untuk pemecahan masalah pemantauan keterbatasan sumber daya yang terbatas (Taha, 1996). Pendekatan riset yang menggunakan program linier merupakan metode ilmiah yang secara khusus dimulai dengan mengamati dan merumuskan masalah dan kemudian membangun suatu model ilmiah (yang khas matematis) yang berusaha untuk mengabstraksikan inti dari persoalan yang sebenarnya (Hiller, 1990).

Salah satu bagian dari program linear yang dapat dijumpai dalam kehidupan sekitar adalah masalah penugasan (Assignment Problem). Langkah optimalisasi yang akan di tetapkan harus sesuai dengan yang direncanakan sesuai dengan kemampuan perusahaan tersebut, misalnya dalam pengambilan keputusan yang baik. Penugasan Multi-objective adalah cara dalam pengambilan keputusan, yang berkaitan dengan masalah optimasi matematika yang melibatkan lebih dari satu fungsi tujuan yang akan dioptimalkan secara bersamaan.

\section{TINJAUAN PUSTAKA}

\subsection{Penugasan Multi-Objective}

Raharjo (2010) menyatakan bahwa riset Penugasan Multi-objective adalah metode optimasi dengan beberapa fungsi tujuan yang tunduk pada beberapa batasan, cara dalam pengambilan keputusan yang berkaitan dengan masalah optimasi matematika yang melibatkan lebih dari satu fungsi tujuan yang akan dioptimalkan secara bersamaan. Penugasan multiobjective ini telah diterapkan di berbagai bidang ilmu pengetahuan, dimana keputusan yang optimal perlu diambil dengan adanya pemilihan antara dua tujuan atau lebih yang saling bertentangan. 


\subsection{Metode Hungarian}

Metode ini mula-mula dikembangkan oleh seorang ahli matematika berkebangsaan Hungarian yang bernama D. Koing pada 1916 (Handoko, 2000). Penggunaan prosedur Metode Hungarian dengan matriks berbobot terdiri dari 3 tahap, yaitu penyusunan matriks/tabel penugasan, analisis kelayakan penetapan optimum, dan penyusunan ulang matriks. Secara umum masalah penugasan dibagi menjadi dua yaitu masalah maksimalisasi dan minimalisasi.

\section{METODE PENELITIAN}

Data yang di gunakan dalam penelitian ini adalah data sekunder. Penelitian dilakukan dengan melakukan prosedur di bawah ini

1. Memulai penelitian.

2. Pengambilan data.

3. Menentukan fungsi kendala dan fungsi tujuan masalah penugasan.

4. Pembuatan matriks masalah penugasan.

5. Mengoptimasi masalah Penugasan Multi-objective menggunakan Metode Hungarian.

6. Hasil dan pembahasan.

7. Kesimpulan.

8. Selesai.

\section{HASIL DAN PEMBAHASAN}

\subsection{Hasil Penelitian}

Penelitian ini akan menerapkan metode hungarian untuk mencari solusi optimal dari contoh kasus masalah penugasan multi-objective pada usaha kerajinan kayu hitam di Toko Sumber Urip Ebony yang berada di wilayah Kota Palu. Terdapat 9 pekerja yang memasok barang dan 9 jenis barang produksi kayu hitam, yaitu gantungan kunci (1), alat refleksi (2), asbak (3), tasbih (4), kotak tisu (5), perahu (6), papan nama (7), jam (8), tongkat komando (9). Data penetapan biaya pembuatan produksi dipasok per sepuluh unit (dalam ribuan rupiah), dapat dilihat pada Tabel 1.

Tabel 1: Biaya Penyelesaian souvenir Kayu Hitam

\begin{tabular}{|c|c|c|c|c|c|c|c|c|c|}
\hline \multirow{2}{*}{ Pekerja } & \multicolumn{10}{|c|}{ Jenis Kerajinan } \\
\cline { 2 - 10 } & 1 & 2 & 3 & 4 & 5 & 6 & 7 & 8 & 9 \\
\hline A & 50 & 220 & 250 & 300 & 250 & 550 & 750 & 850 & 10000 \\
\hline B & 100 & 350 & 380 & 400 & 450 & 480 & 1500 & 6000 & 9000 \\
\hline C & 140 & 190 & 200 & 240 & 500 & 4500 & 5000 & 7500 & 8000 \\
\hline D & 110 & 140 & 450 & 750 & 1250 & 3000 & 4500 & 5000 & 6000 \\
\hline E & 40 & 450 & 500 & 550 & 600 & 900 & 1000 & 1800 & 2500 \\
\hline F & 150 & 160 & 400 & 420 & 480 & 800 & 850 & 900 & 1000 \\
\hline G & 120 & 36 & 300 & 320 & 360 & 400 & 500 & 7000 & 7500 \\
\hline
\end{tabular}




\begin{tabular}{|c|c|c|c|c|c|c|c|c|c|}
\hline $\mathrm{H}$ & 130 & 180 & 190 & 200 & 1500 & 2000 & 2500 & 2750 & 3000 \\
\hline $\mathrm{I}$ & 70 & 100 & 150 & 600 & 1000 & 1750 & 2000 & 2500 & 5000 \\
\hline
\end{tabular}

Data penetapan waktu pembuatan (dalam satuan hari kerja) dapat dilihat pada tabel 2.

Tabel 2 : Waktu Penyelesaian souvenir Kayu Hitam

\begin{tabular}{|c|c|c|c|c|c|c|c|c|c|}
\hline \multirow{2}{*}{ Pekerja } & \multicolumn{7}{|c|}{ Jenis Kerajinan } \\
\cline { 2 - 10 } & 1 & 2 & 3 & 4 & 5 & 6 & 7 & 8 & 9 \\
\hline A & 1 & 6 & 3 & 12 & 7 & 16 & 18 & 16 & 21 \\
\hline B & 1 & 3 & 6 & 12 & 5 & 16 & 21 & 20 & 21 \\
\hline C & 2 & 4 & 7 & 12 & 6 & 20 & 20 & 18 & 21 \\
\hline D & 1 & 6 & 2 & 15 & 5 & 19 & 20 & 16 & 25 \\
\hline E & 1 & 4 & 6 & 14 & 7 & 16 & 24 & 16 & 18 \\
\hline F & 2 & 2 & 7 & 12 & 3 & 16 & 24 & 21 & 25 \\
\hline G & 2 & 1 & 7 & 12 & 4 & 16 & 24 & 16 & 21 \\
\hline H & 2 & 5 & 5 & 14 & 6 & 18 & 25 & 16 & 25 \\
\hline I & 1 & 5 & 4 & 12 & 3 & 18 & 30 & 16 & 20 \\
\hline
\end{tabular}

\subsection{Penerapan Metode Hungarian}

4.2.1. Penyelesaian yang hanya mempertimbangkan biaya operasi

Tabel 3 : Penugasan Optimal Pekerja untuk Biaya Penyelesaian souvenir Kayu Hitam

\begin{tabular}{|c|c|c|c|c|c|c|c|c|c|}
\hline \multirow{2}{*}{ Pekerja } & \multicolumn{10}{|c|}{ Jenis Kerajinan } \\
\cline { 2 - 10 } & 1 & 2 & 3 & 4 & 5 & 6 & 7 & 8 & 9 \\
\hline A & 180 & 320 & 300 & 310 & 0 & 170 & 270 & 0 & 9050 \\
\hline B & 130 & 350 & 330 & 310 & 100 & 0 & 920 & 5050 & 7950 \\
\hline C & 20 & 40 & 0 & 0 & 0 & 3870 & 4270 & 6400 & 6800 \\
\hline D & 0 & 0 & 260 & 520 & 760 & 2380 & 3780 & 3910 & 4810 \\
\hline E & 0 & 380 & 380 & 390 & 180 & 350 & 350 & 780 & 1380 \\
\hline F & 230 & 210 & 400 & 380 & 180 & 370 & 320 & 0 & 0 \\
\hline G & 230 & 440 & 330 & 310 & 90 & 0 & 0 & 6130 & 6530 \\
\hline H & 50 & 70 & 30 & 0 & 1040 & 1410 & 1810 & 1690 & 1840 \\
\hline I & 0 & 0 & 0 & 410 & 550 & 1170 & 1320 & 1450 & 3850 \\
\hline
\end{tabular}

Diperoleh total biaya total waktu yang dibutuhkan untuk membuat 9 (sembilan) jenis kayu hitam tersebut adalah sebagai berikut :

Total biaya operasi :

$Z c=850+480+500+140+40+1000+500+200+150=3.860 \quad$ (dalam ribuan rupiah). 
Total waktu operasi :

$Z t=16+16+6+6+1+25+24+14+4=112$ hari

\subsubsection{Penyelesaian yang hanya mempertimbangkan waktu operasi}

Tabel 4 : Penugasan Optimal Pekerja untuk Waktu Penyelesaian souvenir Kayu Hitam

\begin{tabular}{|c|c|c|c|c|c|c|c|c|c|}
\hline \multirow{2}{*}{ Pekerja } & \multicolumn{7}{|c|}{ Jenis Kerajinan } \\
\cline { 2 - 10 } & 1 & 2 & 3 & 4 & 5 & 6 & 7 & 8 & 9 \\
\hline A & 1 & 5 & 1 & 1 & 5 & 1 & 0 & 1 & 3 \\
\hline B & 0 & 1 & 3 & 0 & 2 & 0 & 2 & 4 & 2 \\
\hline C & 1 & 2 & 4 & 0 & 3 & 4 & 1 & 2 & 2 \\
\hline D & 1 & 5 & 0 & 4 & 3 & 4 & 2 & 1 & 7 \\
\hline E & 1 & 3 & 4 & 3 & 5 & 1 & 6 & 1 & 0 \\
\hline F & 1 & 0 & 4 & 0 & 0 & 0 & 5 & 5 & 6 \\
\hline G & 2 & 0 & 5 & 1 & 2 & 1 & 6 & 1 & 3 \\
\hline H & 1 & 3 & 2 & 2 & 3 & 2 & 6 & 0 & 6 \\
\hline I & 0 & 3 & 1 & 0 & 0 & 2 & 11 & 0 & 1 \\
\hline
\end{tabular}

Diperoleh total biaya dan total waktu yang diperlukan untuk membuat 9 (sembilan) jenis kerjainan tersebut adalah sebagai berikut :

Total biaya operasi :

$Z c=750+100+400+200+6000+900+360+2750+1000=$ 12.460 (ribuan rupiah)

Total waktu operasi :

$Z t=18+1+12+2+18+16+1+16+3=87$ hari

\subsubsection{Penyelesaian yang hanya mempertimbangkan biaya dan waktu operasi}

Menormalkan semua data, yaitu proses penyetoran semua data dengan cara membagi data biaya dan waktu masing-masing dengan nilai tertinggi pada masingmasing kolom adalah 10.000 dan 30 . Hasil pernormalan data biaya dan waktu dari Tabel 1 dan 2 dapat dilihat pada Tabel 5.

Tabel 5 : Data Penormalan Biaya dan Waktu

\begin{tabular}{|c|c|c|c|c|c|c|c|c|c|}
\hline \multirow{2}{*}{ Pekerja } & \multicolumn{10}{|c|}{ Jenis Kerajinan } \\
\cline { 2 - 10 } & 1 & 2 & 3 & 4 & 5 & 6 & 7 & 8 & 9 \\
\hline \multirow{2}{*}{ A } & 0,005 & 0,022 & 0,025 & 0,03 & 0,025 & 0,055 & 0,075 & 0,085 & 1 \\
& 0,033 & 0,2 & 0,1 & 0,4 & 0,233 & 0,533 & 0,6 & 0,533 & 0,7 \\
\hline \multirow{2}{*}{ B } & 0,01 & 0,035 & 0,038 & 0,04 & 0,045 & 0,048 & 0,15 & 0,6 & 0,9 \\
& 0,033 & 0,1 & 0,2 & 0,4 & 0,167 & 0,533 & 0,7 & 0,667 & 0,7 \\
\hline \multirow{2}{*}{ C } & 0,014 & 0,019 & 0,02 & 0,024 & 0,05 & 0,45 & 0,5 & 0,75 & 0,8 \\
& 0,067 & 0,133 & 0,233 & 0,4 & 0,2 & 0,667 & 0,667 & 0,6 & 0,7 \\
\hline
\end{tabular}




\begin{tabular}{|c|c|c|c|c|c|c|c|c|c|}
\hline \multirow{2}{*}{$\mathrm{D}$} & 0,011 & 0,014 & 0,045 & 0,075 & 0,125 & 0,3 & 0,45 & 0,5 & 0,6 \\
& 0,033 & 0,2 & 0,067 & 0,5 & 0,167 & 0,633 & 0,667 & 0,533 & 0,833 \\
\hline \multirow{2}{*}{$\mathrm{E}$} & 0,004 & 0,045 & 0,05 & 0,055 & 0,06 & 0,09 & 0,1 & 0,18 & 0,25 \\
& 0,033 & 0,133 & 0,2 & 0,467 & 0,233 & 0,533 & 0,667 & 0,533 & 0,833 \\
\hline \multirow{2}{*}{$\mathrm{F}$} & 0,015 & 0,016 & 0,04 & 0,042 & 0,048 & 0,08 & 0,085 & 0,09 & 0,1 \\
& 0,067 & 0,067 & 0,233 & 0,4 & 0,1 & 0,533 & 0,8 & 0,7 & 0,833 \\
\hline \multirow{2}{*}{$\mathrm{G}$} & 0,12 & 0,036 & 0,03 & 0,032 & 0,036 & 0,04 & 0,05 & 0,7 & 0,75 \\
& 0,067 & 0,033 & 0,233 & 0,4 & 0,133 & 0,533 & 0,8 & 0,533 & 0,7 \\
\hline \multirow{2}{*}{$\mathrm{H}$} & 0,013 & 0,018 & 0,019 & 0,02 & 0,15 & 0,2 & 0,25 & 0,275 & 0,3 \\
& 0,067 & 0,167 & 0,167 & 0,467 & 0,2 & 10,6 & 0,833 & 0,533 & 0,833 \\
\hline \multirow{2}{*}{$\mathrm{I}$} & 0,007 & 0,01 & 0,015 & 0,06 & 0,1 & 0,175 & 0,2 & 0,25 & 0,5 \\
& 0,033 & 0,167 & 0,133 & 0,4 & 0,1 & 0,6 & 1 & 0,533 & 0,667 \\
\hline
\end{tabular}

Normalisasi data tidak mempengaruhi hasil keputusan dari masalah penugasan. Karena jika setiap elemen atau nilai dari suatu tabel penugasan dikalikan atau dibagi dengan sebuah nilai skalar yang sama, maka setiap elemen atau nilai yang dihasilkan mempunyai perbandingan yang sama dengan setiap elemen atau nilai pada tabel penugasan sebelumnya. Oleh karena itu, meskipun nilai yang dihasilkan dari tabel penugasan mengalami perubahan, akan tetapi hasil keputusan penetapan dari masalah penugasan tersebut tetap sama, karena mempunyai perbandingan nilai yang sama (Raharjo, 2010).

Selanjutnya menjumlahkan dari masing-masing kolom pada Tabel 5 pada penjumlahan data penormalan biaya dan waktu dapat dilihat pada Tabel 6.

Tabel 6 : Penjumlahan Data Penormalan Biaya dan Waktu

\begin{tabular}{|c|c|c|c|c|c|c|c|c|c|}
\hline \multirow{2}{*}{ Pekerja } & \multicolumn{10}{|c|}{ Jenis Kerajinan } \\
\cline { 2 - 10 } & 1 & 2 & 3 & 4 & 5 & 6 & 7 & 8 & 9 \\
\hline A & 0,038 & 0,222 & 0,125 & 0,43 & 0,258 & 0,588 & 0,675 & 0,618 & 1,7 \\
\hline B & 0,043 & 0,135 & 0,238 & 0,44 & 0,211 & 0,581 & 0,85 & 1,266 & 1,6 \\
\hline C & 0,080 & 0,152 & 0,253 & 0,424 & 0,25 & 1,117 & 1,167 & 1,35 & 1,5 \\
\hline D & 0,044 & 0,214 & 0,112 & 0,575 & 0,291 & 0,933 & 1,117 & 1,033 & 1,433 \\
\hline E & 0,037 & 0,178 & 0,25 & 0,522 & 0,293 & 0,623 & 0,9 & 0,713 & 0,85 \\
\hline F & 0,081 & 0,082 & 0,273 & 0,442 & 0,148 & 0,613 & 0,885 & 0,79 & 0,933 \\
\hline G & 0,078 & 0,069 & 0,263 & 0,432 & 0,169 & 0,573 & 0,85 & 1,233 & 1,45 \\
\hline H & 0,113 & 0,184 & 0,186 & 0,487 & 0,35 & 0,8 & 1,083 & 0,808 & 1,133 \\
\hline I & 0,040 & 0,176 & 0,148 & 0,46 & 0,2 & 0,775 & 1,2 & 0,783 & 1,166 \\
\hline
\end{tabular}

Langkah berikutnya adalah untuk menyelesaikan kedua tujuan secara bersamaan, yaitu meminimumkan baik biaya operasi maupun waktu operasi karena proses penyelesaian mempertimbangkan dua jenis sumber daya, maka secara sistematis bobot dari masing-masing tujuan harus ditetapkan terlebih dahulu, agar dapat 
mengetahui sumber daya mana yang lebih penting daripada sumber daya yang lain ataupun tingkat kepentingan dari masing-masing tujuan tersebut.

Diasumsikan bahwa bobot dari dua tujuan tersebut mempunyai tingkat kepentingan yang sama, $\alpha=\alpha_{1}=\alpha_{2}=\ldots=\alpha_{m}$, dengan $\alpha=\frac{1}{m}$ dimana $m$ adalah banyaknya tujuan, dengan $\sum_{i=1}^{m} \alpha_{i}=1$. Kemudian fungsi tujuan dapat ditulis menjadi:

Minimumkan

$Z c, Z t=\alpha_{1} \sum_{i=1}^{N} \sum_{j=1}^{N} c_{i j} x_{i j}+L_{2} \sum_{i=1}^{N} \sum_{j=l}^{N} t_{i j} x_{i j}$

$c_{I J}$ dan $t_{i j}$ masing-masing mewakili normalisasi biaya operasi dan waktu operasi. Menggunakan normalisasi data biaya dan waktu pada Tabel 6 dan memberikan bobot $\alpha_{1}=\alpha_{2}=\frac{1}{2}$. Tabel matrik biaya dan waktu dapat dilihat pada Tabel 7 .

Tabel 7: Matriks Biaya dan Waktu

\begin{tabular}{|c|c|c|c|c|c|c|c|c|c|}
\hline \multirow{2}{*}{ Pekerja } & \multicolumn{8}{|c|}{ jumlah penormalan biaya dan waktu } \\
\cline { 2 - 10 } & 1 & 2 & 3 & 4 & 5 & 6 & 7 & 8 & 9 \\
\hline A & 0,019 & 0,111 & 0,06 & 0,22 & 0,129 & 0,294 & 0,338 & 0,31 & 0,85 \\
\hline B & 0,021 & 0,068 & 0,12 & 0,22 & 0,106 & 0,291 & 0,425 & 0,63 & 0,8 \\
\hline C & 0,040 & 0,076 & 0,13 & 0,21 & 0,125 & 0,558 & 0,583 & 0,68 & 0,75 \\
\hline D & 0,022 & 0,107 & 0,06 & 0,29 & 0,146 & 0,467 & 0,558 & 0,52 & 0,717 \\
\hline E & 0,018 & 0,089 & 0,13 & 0,26 & 0,147 & 0,312 & 0,45 & 0,36 & 0,425 \\
\hline F & 0,040 & 0,041 & 0,14 & 0,22 & 0,074 & 0,307 & 0,443 & 0,4 & 0,467 \\
\hline G & 0,039 & 0,035 & 0,13 & 0,22 & 0,085 & 0,287 & 0,425 & 0,62 & 0,725 \\
\hline H & 0,056 & 0,092 & 0,09 & 0,24 & 0,175 & 0,4 & 0,542 & 0,4 & 0,567 \\
\hline I & 0,020 & 0,088 & 0,07 & 0,23 & 0,1 & 0,388 & 0,6 & 0,39 & 0,583 \\
\hline
\end{tabular}

Solusi penetapan disesuaikan dengan menggunakan metode Hungarian dapat dilihat pada Tabel 8.

Tabel 8 : Penugasan Optimal Pekerja untuk Biaya dan Waktu Penyelesaian souvenir Kayu Hitam

\begin{tabular}{|c|c|c|c|c|c|c|c|c|c|}
\hline \multirow{2}{*}{ Pekerja } & \multicolumn{10}{|c|}{ Jenis Kerajinan } \\
\cline { 2 - 10 } & 1 & 2 & 3 & 4 & 5 & 6 & 7 & 8 & 9 \\
\hline A & 0,06 & 0,11 & 0,06 & 0,07 & 0,09 & 0,03 & 0,00 & 0,00 & 0,42 \\
\hline B & 0,03 & 0,04 & 0,09 & 0,04 & 0,04 & 0,00 & 0,06 & 0,29 & 0,34 \\
\hline C & 0,02 & 0,02 & 0,07 & 0,00 & 0,03 & 0,24 & 0,18 & 0,31 & 0,26 \\
\hline D & 0,00 & 0,05 & 0,00 & 0,08 & 0,05 & 0,15 & 0,16 & 0,15 & 0,23 \\
\hline E & 0,06 & 0,09 & 0,13 & 0,11 & 0,11 & 0,05 & 0,11 & 0,05 & 0,00 \\
\hline F & 0,05 & 0,01 & 0,11 & 0,04 & 0,00 & 0,02 & 0,07 & 0,06 & 0,01 \\
\hline G & 0,05 & 0,00 & 0,10 & 0,04 & 0,01 & 0,00 & 0,06 & 0,28 & 0,27 \\
\hline
\end{tabular}




\begin{tabular}{|c|c|c|c|c|c|c|c|c|c|}
\hline $\mathrm{H}$ & 0,01 & 0,00 & 0,00 & 0,00 & 0,05 & 0,05 & 0,11 & 0,00 & 0,05 \\
\hline $\mathrm{I}$ & 0,00 & 0,03 & 0,01 & 0,02 & 0,00 & 0,07 & 0,20 & 0,02 & 0,09 \\
\hline
\end{tabular}

Diperoleh total biaya dan total waktu yang dibutuhkan untuk membuat 9 (sembilan) jenis kerajinan tersebut adalah sebagai berikut :

Total biaya operasi :

$Z c=750+480+240+450+2500+480+360+2750+70=8.080$ (ribuan rupiah)

Total waktu operasi :

$Z t=18+16+12+2+18+3+1+16+1=87$ hari

\subsection{Pembahasan}

Ketika mempertimbangkan masalah penugasan multi-objective untuk mendapatkan hasil yang optimal, maka fungsi multi-objective dapat ditulis sebagai berikut :

$$
\begin{aligned}
& \operatorname{Min} Z_{1}, Z_{2}, \ldots, Z_{m}=\alpha_{1} \sum_{i=l}^{N} \sum_{j=l}^{N} Z_{i j} x_{i j}+\alpha_{2} \sum_{j=l}^{N} \sum_{i=l}^{N} \sum_{j=l}^{N} Z_{i j} x_{i}+\ldots+ \\
& \alpha_{m} \sum_{i=l}^{N} \sum_{j=l}^{N} Z_{m i j} x_{i j}
\end{aligned}
$$

Dimana $Z_{i}$ menunjukkan jenis sumber daya yang harus dioptimalkan dan $\alpha_{1}$ adalah bobot dari sumber daya $i$, dengan $\sum_{i=l}^{m} \alpha_{i}=1$.Untuk mempermudah dalam malihat perbandingan hasil dari penyelesaian sebelumnya, maka daftar hasil tersebut disusun dalam Tabel 9.

\begin{tabular}{|c|c|c|c|c|}
\hline No & Objective & Solusi & $\begin{array}{c}\text { Total } \\
\text { biaya } \\
\text { (ribuan } \\
\text { rupiah) }\end{array}$ & $\begin{array}{l}\text { Total } \\
\text { waktu } \\
\text { (hari) }\end{array}$ \\
\hline 1 & $\begin{array}{c}\text { Hanya } \\
\text { mempertimbangkan } \\
\text { biaya operasi }\end{array}$ & $\begin{aligned} x_{18} *=x_{26} *= & x_{35} *=x_{42} *=x_{51} * \\
& =x_{69} *=x_{77} *=x_{84} * \\
& =x_{93} *=1\end{aligned}$ & 3.860 & 112 \\
\hline 2 & $\begin{array}{l}\text { Hanya } \\
\text { mempertimbangkan } \\
\text { waktu operasi }\end{array}$ & $\begin{aligned} x_{17} *=x_{21} *= & x_{34} *=x_{43} *=x_{59} * \\
& =x_{66} *=x_{72} *=x_{88} * \\
& =x_{95} *=1\end{aligned}$ & 12.460 & 87 \\
\hline 3 & $\begin{array}{c}\text { Mempertimbangkan } \\
\text { biaya operasi dan } \\
\text { waktu operasi }\end{array}$ & $\begin{aligned} x_{17} *=x_{26} *= & x_{34} *=x_{43} *=x_{59} * \\
& =x_{65} *=x_{72} *=x_{88} * \\
& =x_{91} *=1\end{aligned}$ & 8.080 & 87 \\
\hline
\end{tabular}

Tabel 9 : Hasil Proses Optimasi

Dari Tabel 9 dapat dilihat bahwa proses optimasi yang hanya mempertimbangkan waktu operasi dan yang mempertimbangkan sumber daya ketiganya secara bersamaan ternyata mempunyai hasil yang sama. Hal ini tidak berlaku umum hanya untuk kasus diatas, karena 
apabila hanya mempertimbangkan waktu operasi saja, maka hanya dapat dipastikan akan menghasilkan nilai yang optimal pada sumber daya waktu tersebut, akan tetapi belum dapat dipastikan akan menghasilkan nilai penugasan yang optimal bagi sumber daya yang lain. Dapat disimpulkan bahwa, jika proses optimasi pada masalah penugasan multi-objective hanya mempertimbangkan salah satu sumber daya saja, maka hanya menghasilkan nilai optimal bagi sumber daya tersebut dan belum tentu menghasilkan nilai optimal bagi sumber daya yang lain. Oleh karena itu proses optimasi yang mempertimbangkan semua sumber daya yang ada secara bersamaan menunjukkan hasil yang terbaik dari pada proses optimasi yang lain dan sudah dapat dipastikan menghasilkan nilai yang optimal pada masing-masing sumber daya yang ada. Jadi total biaya yang dikeluarkan untuk memproduksi semua jenis kerajinan adalah Rp. 8.080.000,- dengan total waktu 87 hari. Perhitungan multi- objective ini menunjukkan hasil yang lebih efisien bila dibandingkan dengan biaya yang dikeluarkan sebesar Rp. 12.650.000,dengan total waktu 115 hari pada Toko Sumber Urip Ebony.

\section{KESIMPULAN}

Berdasarkan penelitian yang telah dilakukan maka disimpulkan bahwa hasil biaya dan waktu pengerjaan menggunakan penugasan multi-objective metode Hungaria adalah Rp.8.080.000,- dengan total waktu 87 hari. Biaya dan waktu pengerjaan tanpa menggunakan penugasan multi-objective metode Hungaria adalah Rp. 12.650.000,- dengan total waktu 115 hari. Hal ini menunjukan bahwa proses pengerjaan menggunakan penugasan multi-objective dengan metode Hungarian memiliki hasil yang lebih optimal.

\section{DAFTAR PUSTAKA}

[1]. Anonim, Iso Farmakoterapi, PT. ISFI Penerbitan, 2008, Jakarta.

[2]. Handoko, T. H, Dasar-Dasar Manajemen Produksi dan Operasi, Edisi Pertama, 2000, Yogyakarta: BPFE.

[3]. Hiller, F. S, Pengantar Riset Operasional, Erlangga, 1990, Jakarta.

[4]. Raharjo, D, Proses Optimasi dan Idealisasi Masalah Penugasan Multi-objectiveMenggunakan Metode Hungaria pada Contoh Kasus Usaha Gitar di Ngrombo Baki Sukoharjo, Skripsi, Fakultas Matematika dan IImu Pengetahuan Alam, Universitas Sebelas Maret, 2010, Surakarta.

[5]. Taha, Hamdy A, Riset Operasi Edisi Kelima: Penerbit Binarupa Aksara, 1996, Tangerang. 